\title{
EVOLUÇÃO DO CONTROLE OPERACIONAL DO ALTO FORNO 1 DA TKCSA*
}

\author{
André Wulff Hirano' \\ Bruno Pinheiro da Silva² \\ Erick Torres Bispo dos Santos ${ }^{3}$ \\ Valdir Fernandes Ramos ${ }^{4}$
}

\section{Resumo}

O Alto Forno 01 da ThyssenKrupp CSA entrou em operação em 12/07/2010 dando inicio a uma etapa em que o Brasil recebeu sua mais recente usina integrada, sendo um marco no modelo de planta compacta com o nível de capacidade instalada de 5 milhões ton/ano de placas. O modelo de controle de fluxo gasoso centralizado e com baixa marcha periférica havia se mostrado não adequado. Desse modo, foi implementado um monitoramento de indicadores para auxiliar na avaliação e controle de nível térmico e de distribuição de gás. Logrou-se obter uma estabilização da marcha do Alto Forno resultando em um melhor desempenho nas condições de escoamento, melhor rendimento de gás e, por consequência, redução do Fuel Rate, além de uma otimização no custo de carga metálica. Este trabalho mostra o desenvolvimento das práticas operacionais e de controle que permitiram essa evolução nos resultados.

Palavras-chave: Distribuição de carga; Controle térmico.

\section{OPERATIONAL CONTROL AT TKCSA \# 01 BLAST FURNACE}

\begin{abstract}
TKCSA \#01 Blast Furnace was blow in at 2010 July 12th starting the newest integrated steel plant in the world. It is remarkable since it is a model of compact plant to produce 5,0 Mt of slabs. Strong central gas flow and low wall flow model used since the blow-in was shown not suitable. So new parameters was implemented to help in operational and thermal control and gas distribution adjusts. A stable BF operation was established and leading to a better gas gas flow as well a better gas utilization and lowering coke rate became possible, as an optimizing burden costs. This paper shows the development of the operational control and practices that allowed those results.
\end{abstract}

Keywords: Burden distribution; BF operation; Thermal control.

1 Engenheiro Metalurgista, Engenheiro de Processo, Unidade Técnica da Redução, TKCSA, Rio de Janeiro, RJ, Brasil.

2 Graduando em Engenharia química, Especialista de Alto Forno, Unidade Técnica da Redução, TKCSA, Rio de Janeiro, RJ, Brasil.

3 Engenheiro Metalurgista, M.Sc, Gerente de Unidade Técnica, Unidade Técnica da Redução, TKCSA, Rio de Janeiro, RJ, Brasil.

4 Coordenador de Operação do Alto Forno 01, TKCSA, Rio de Janeiro, RJ, Brasil.

* Contribuição técnica ao 44 Seminário de Redução de Minério de Ferro e Matérias-primas, 15ㅇ Simpósio Brasileiro de Minério de Ferro e 2o Simpósio Brasileiro de Aglomeração de Minério de Ferro, 15 a 18 de setembro de 2014, Belo Horizonte, MG, Brasil. 


\section{INTRODUÇÃO}

Passados quase 30 anos após o último start up, o blow in do Alto Forno 01 da TKCSA (ThyssenKrupp Companhia Siderúrgica do Atlântico), marcou o início de operação de uma usina siderúrgica integrada, porém com novos conceitos de layout. Trata-se um uma usina integrada para produção de placas com capacidade de produção para 5,0 Mt, ocupando uma área menor que as usinas "tradicionais", utilizando soluções pouco ortodoxas.

Conta com dois Altos Fornos de $3284 \mathrm{~m}^{3}$ de volume interno, uma sinterização de $456 \mathrm{~m}^{2}$ e 3 baterias de coque com 144 fornos, do tipo heat recovery, e uma capacidade de geração de energia elétrica de $490 \mathrm{MW}$, reaproveitando os gases de Coqueria, Alto Forno e Aciaria.

\section{DESENVOLVIMENTO}

Como pode ser observado na figura 1 a TKCSA apresenta um layout linear, procurando otimizar a questão logística.

Com uma configuração singular a coqueria, sinterização, altos-fornos e aciaria, encontram-se alinhados. É interessante notar que tanto coque quanto sinter, (incluindo materiais oriundos dos pátios) são levados aos Altos fornos por linhas únicas, o que confere uma grande economia e praticidade nas instalações. Os pátios recebem apenas os materiais que serão consumidos, não havendo praticamente pátios primários.

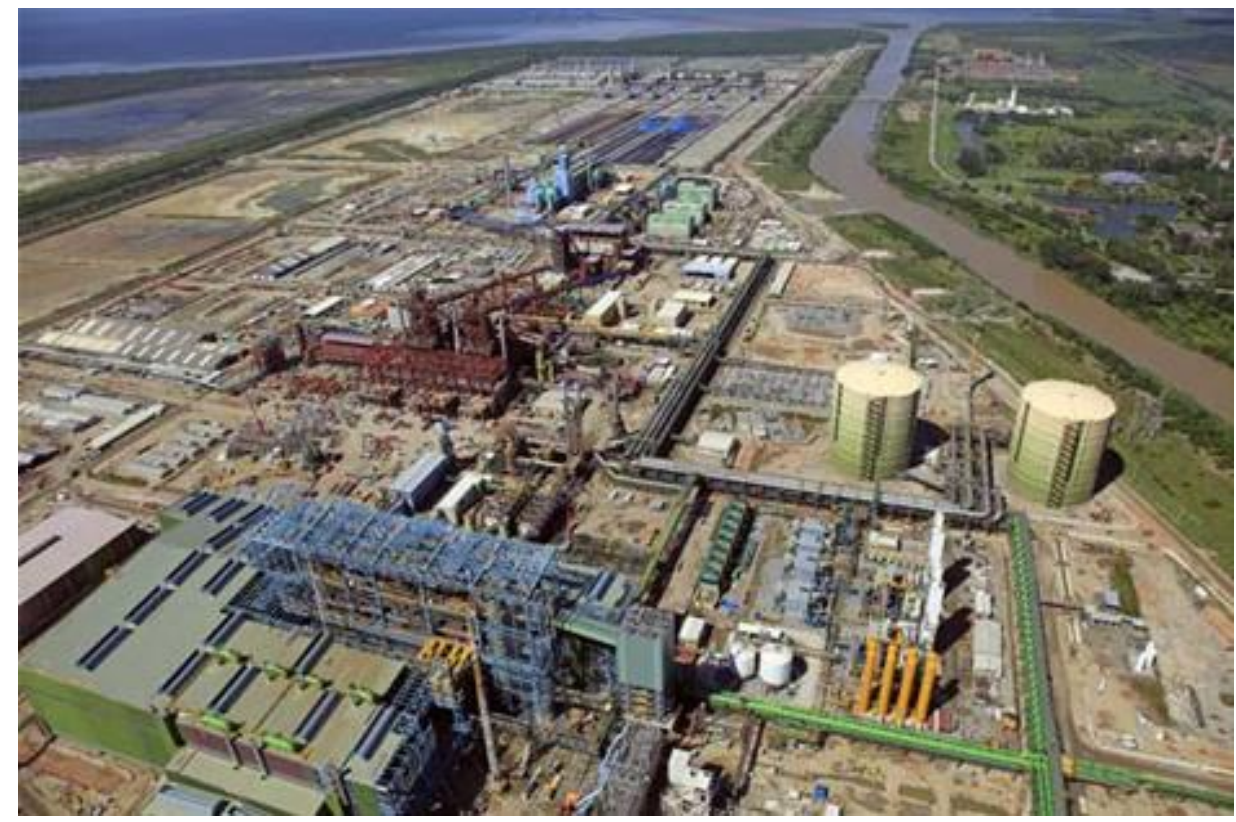

Figura 1 - Layout da planta

Como pode ser visto na tabela 1 encontram-se as principais características de projeto dos fornos da CSA, em que basicamente trata-se de um conceito de Alto Forno com capacidade nominal de 7500 ton/dia, três regeneradores de combustão externas e 32 ventaneiras.

\footnotetext{
* Contribuição técnica ao 44ํㅗㄴ Seminário de Redução de Minério de Ferro e Matérias-primas, 15ํ Simpósio Brasileiro de Minério de Ferro e $2^{\circ}$ Simpósio Brasileiro de Aglomeração de Minério de Ferro, 15 a 18 de setembro de 2014, Belo Horizonte, MG, Brasil.
} 
Tabela 1 - Dados de projeto dos Alto Fornos da CSA

\begin{tabular}{|c|c|}
\hline \multicolumn{2}{|c|}{ DADOS DE PROJETO DOS ALTOS FORNOS } \\
\hline Produção & 5,3 milhões / ano \\
\hline Produção / dia/ AF & 7.500 toneladas \\
\hline Produtividade & 2.28 \\
\hline Indice de disponibilidade & $>97 \%$ \\
\hline Coke Rate & $350 \mathrm{~kg} / \mathrm{thm}$ \\
\hline PCR & $160 \mathrm{~kg} / \mathrm{thm}$ \\
\hline Fuel rate & $510 \mathrm{~kg} / \mathrm{thm}$ \\
\hline Volume Interno & $3.284 \mathrm{~m}^{3}$ \\
\hline Volume de trabalho & $2.775 \mathrm{~m}^{3}$ \\
\hline Diâmetro do cadinho & $12.0 \mathrm{~m}$ \\
\hline Diâmetro da goela (Throat) & $8.5 \mathrm{~m}$ \\
\hline \multicolumn{2}{|c|}{ REGENERADORES } \\
\hline Regeneradores & 3 \\
\hline Temperatura sopro & $1250^{\circ} \mathrm{C}$ \\
\hline Superfície de aquecimento & $54355 \mathrm{~m} 2$ \\
\hline Temperatura do domo & $1485^{\circ} \mathrm{C}$ \\
\hline Temperatura da Chaminé & $450^{\circ} \mathrm{C}$ \\
\hline Poder calorífico gás de topo & 2800 a $3600 \mathrm{kj} / \mathrm{m} 3$ \\
\hline Taxa de gas de topo por regenerador & $66.820 \mathrm{~m} 3 / \mathrm{h}$ \\
\hline Taxa de ar para combustão por regenerador & $108.049 \mathrm{~m} 3 / \mathrm{h}$ \\
\hline \multicolumn{2}{|c|}{ TOPO DO FORNO } \\
\hline \multicolumn{2}{|c|}{ "Bell less , Paul Wurth System } \\
\hline Quantidade de Silos & 2 \\
\hline Capacidade dos silos & $70 \mathrm{~m} 3$ - cada \\
\hline Pressão de topo & 2,5 bar \\
\hline Temperatura gás de topo & $150-200^{\circ} \mathrm{C}$ \\
\hline \multicolumn{2}{|c|}{ INJEÇÃO DE CARVÃO PULVERIZADO } \\
\hline Taxa injeção de carvão (coal) & $50 \mathrm{t} / \mathrm{h}-160 \mathrm{~kg} /$ ton de gusa \\
\hline Taxa injeção de carvão (coal) max. & $220 \mathrm{~kg} / \mathrm{ton}$ de gusa \\
\hline Quantidade de Silos / capacidade & $101 \times 1200 \mathrm{~m} 3$ \\
\hline Quantidade Vaso de injeção / capacidade & 2 para cada forno $-30 \mathrm{~m} 3$ \\
\hline
\end{tabular}

\subsection{Blow in}

O blow in do AF01 (Alto Forno 01) deu-se em 12/07/2010 marcando o início da produção de gusa da ThyssenKrupp no Brasil. Referente aos preparativos, o enchimento do Alto Forno foi feito da maneira usual, com dormentes no cadinho, lançados de modo randômico e com elevação gradativa da relação $\mathrm{m} / \mathrm{c}$ até $3,2 \mathrm{~m}$ de nível de sonda da carga no topo. Conforme mostrado na figura 2.

\footnotetext{
* Contribuição técnica ao 44온 Seminário de Redução de Minério de Ferro e Matérias-primas, 15ํ Simpósio Brasileiro de Minério de Ferro e $2^{\circ}$ Simpósio Brasileiro de Aglomeração de Minério de Ferro, 15 a 18 de setembro de 2014, Belo Horizonte, MG, Brasil.
} 


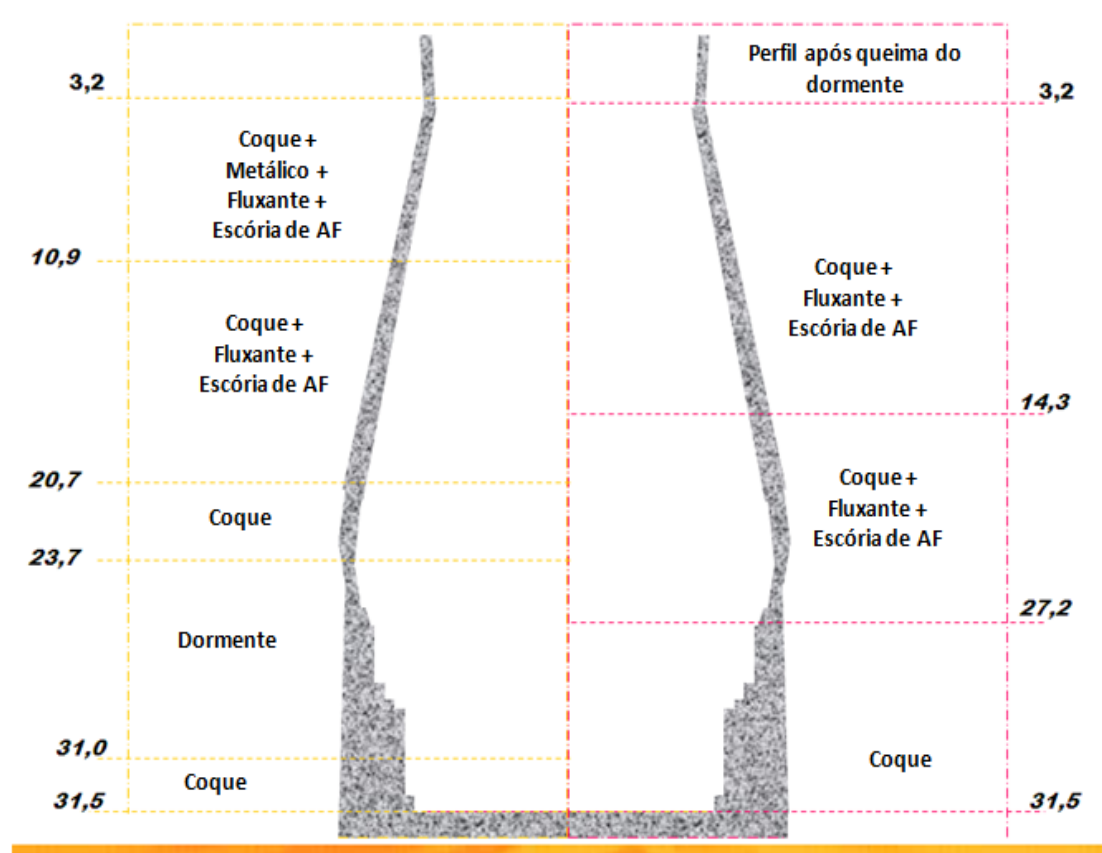

Figura 2 - Perfil de enchimento

A primeira fase de operação do AF01 é marcada pela elevação de produção de acordo com o Figura 3, onde se procurava a aprendizagem dos equipamentos. Foi planejada para atingir $1,9 \mathrm{t} / \mathrm{d} / \mathrm{m}^{3}$ de produtividade até o $3^{\circ}$ mês de operação, não logrando êxito notadamente com a injeção de carvão.

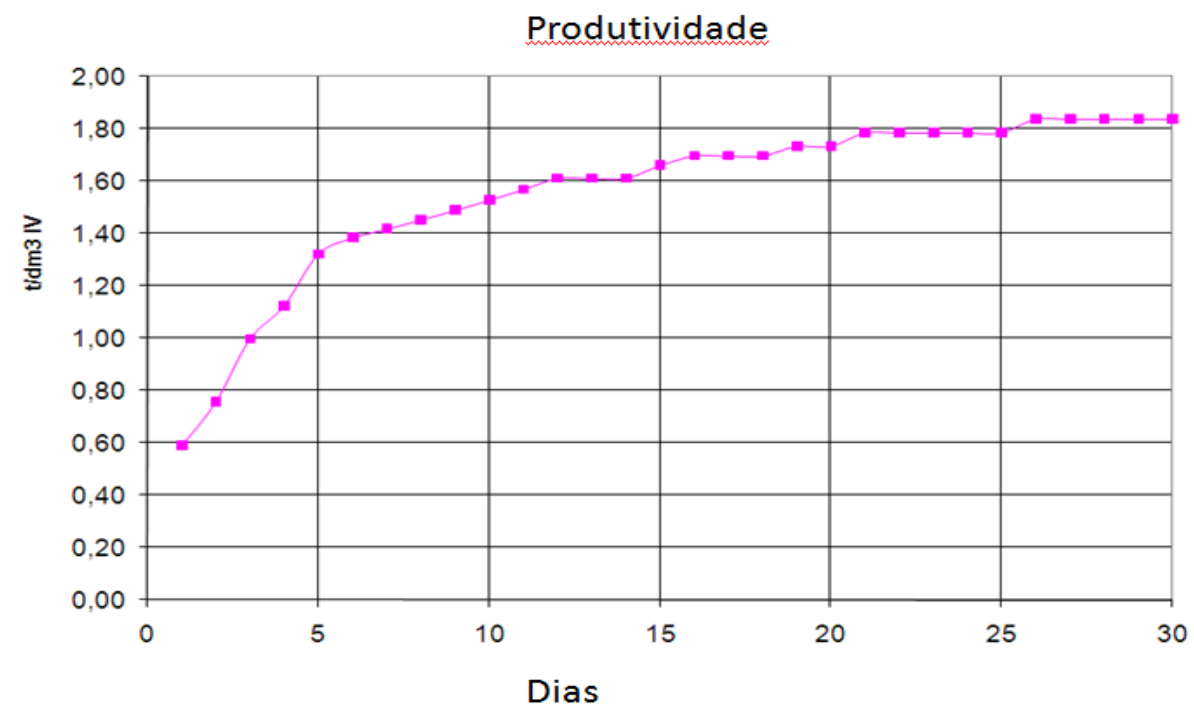

Figura 3. Curva de ramp up de produção

\section{MATERIAIS E MÉTODOS}

O AF01 da CSA teve uma trajetória peculiar e não convencional no ponto de vista de sistemas de informação e aquisição de dados. Nasceu sem a existência de um sistema de nível 2 adequado, o que trouxe desafios na configuração inicial e desenvolvimento de uma identidade operacional. Assim, o passo inicial foi a implantação de um modelo preliminar de manipulação de dados operacionais a partir da obtenção de dados via nível 1 e PIMS. O modelo é baseado em cálculo técnicos,

* Contribuição técnica ao $44^{\circ}$ Seminário de Redução de Minério de Ferro e Matérias-primas, 15ํ Simpósio Brasileiro de Minério de Ferro e $2^{\circ}$ Simpósio Brasileiro de Aglomeração de Minério de Ferro, 15 a 18 de setembro de 2014, Belo Horizonte, MG, Brasil. 
visando contribuir nas tomadas de decisão de acordo com as necessidades do processo.

Durante a fase inicial, que contemplaria os dois primeiros anos de vida do AF01, o grande número de paradas emergenciais foi um obstáculo relevante na garantia da continuidade operacional, mostrado na Figura 4. Juntamente, as condições de elevada variação na qualidade das matérias-primas (referente a dispersão granulométrica do coque e sinter) e gargalos nas interfaces entre as unidades operacionais, comprometeu a busca por melhores resultados naquela ocasião.

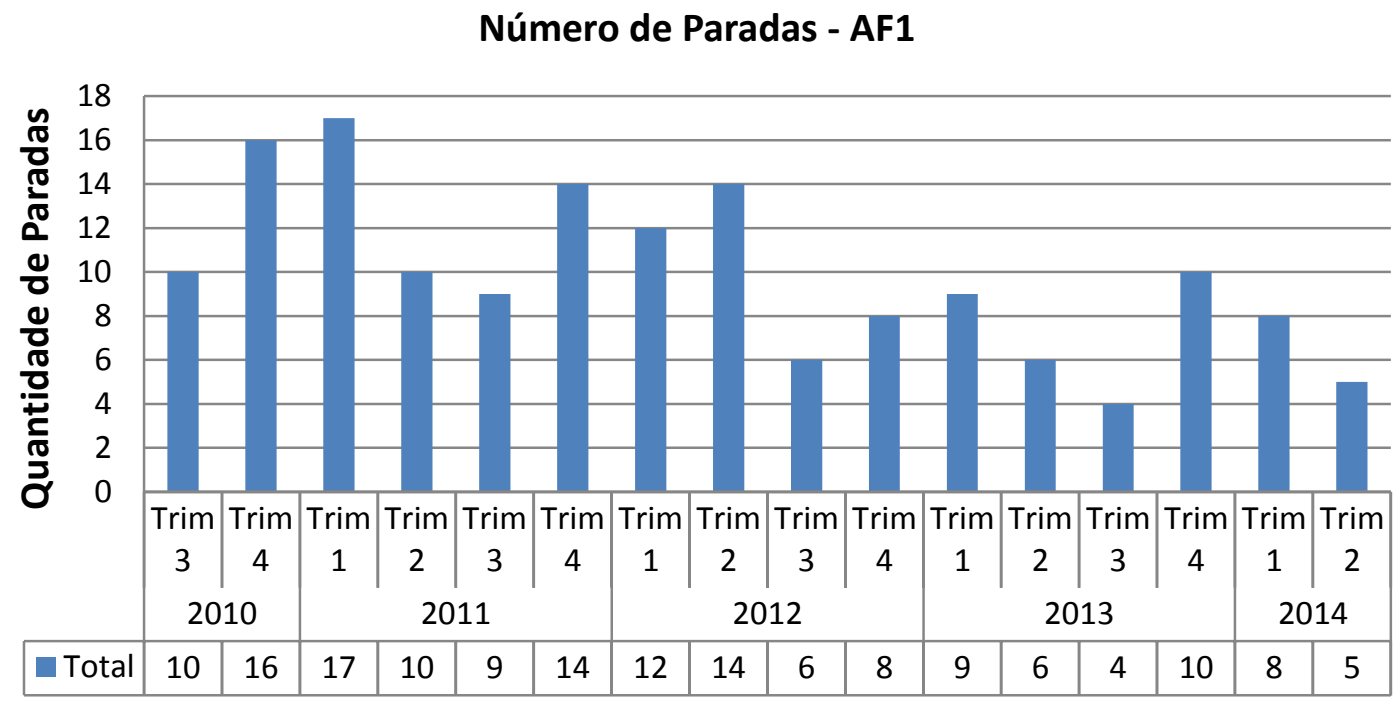

Figura 4. Número de paradas por trimestre, programadas e não programadas.

\subsection{Metodologia de Controle de Processo}

Com a organização inicial da planta formaram-se equipes oriundas de diversas áreas industriais, inclusive com experiência prévia provenientes de outros Altos Fornos. Entretanto, as adversidades trazidas por meio de instabilidades de processo e quedas bruscas de nível térmico foram fatores decisivos para necessidade de ênfase em treinamento. O maior foco deu-se em uniformizar a cultura operacional e padronizar as atuações de controle térmico.

Foi estabelecida a utilização de indicadores de processo de previsibilidade como suporte aos operadores. Além da implementação de restrições e planos de contingências aos desvios operacionais.

As principais medidas foram:

1. Aprimoramento de sistemas de automação como nível 2 e planilhas de controle. Utilização de indicadores como Redução Direta, Balanço Entalpico e Índice de Permeabilidade;

2. Contramedidas para balanço de gusa/escória desfavoráveis, com uso de procedimentos de corridas em paralelo;

3. Elaboração de planos operacionais/contingenciais como orientação aos operadores;

4. Readequação das rotinas de análises das matérias-primas e atualização em leito de fusão;

5. Maior confiabilidade e disponibilidade dos equipamentos;

6. Ajustes na distribuição de carga.

\footnotetext{
* Contribuição técnica ao $44^{\circ}$ Seminário de Redução de Minério de Ferro e Matérias-primas, 15ํ Simpósio Brasileiro de Minério de Ferro e $2^{\circ}$ Simpósio Brasileiro de Aglomeração de Minério de Ferro, 15 a 18 de setembro de 2014, Belo Horizonte, MG, Brasil.
} 


\subsection{Evolução da Distribuição de Carga}

O modelo inicial de contramedidas para escapadas do fluxo de gás pela periferia foi baseado em parte pela migração de material metálico em direção aos anéis adjacentes a parede do forno. Tal ideia era dada com foco em suavizar o descontrole das temperaturas dos Staves (dado pela medição de carga térmica). Com o consumo específico de combustíveis em patamares elevados e junto com o perfil de distribuição adotado, contribuía em trazer a zona de coesão para baixo. Assim sendo, identificava-se uma grande dificuldade na estabilização da marcha periférica e trazendo impactos nas condições de escoamento do cadinho. A condição de fluxo de gás mais "abafada" nas paredes influenciou no menor tempo de vida útil de ventaneiras por queima ou deslocamento, já que constantemente o AF01 apresentava irregularidades na descida de carga. A ideia pode ser vista pela figura 5, gerada pelo modelo Thybas adotado na TKCSA.

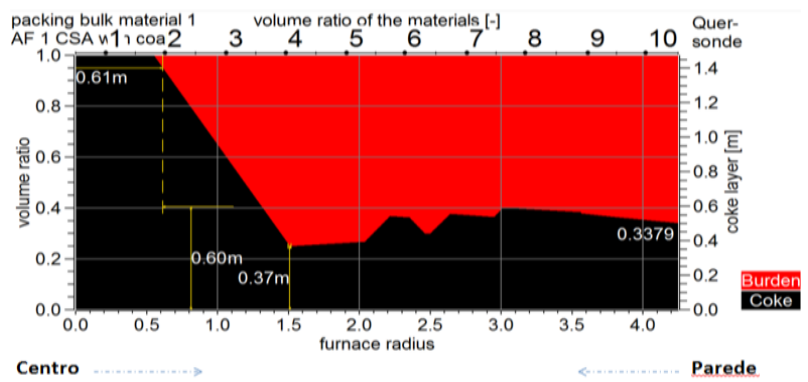

Figura 5. Perfil de distribuição de carga com marcha periférica reduzida, modelo Thybas.

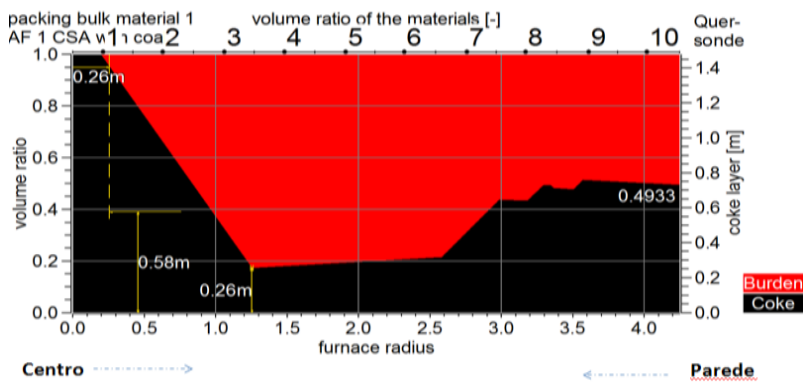

Figura 6. Perfil de distribuição de carga com marcha periférica mais acentuada, modelo Thybas.

A demanda constante por redução de custos e busca por atendimento ao plano de produção motivou a ideia de "pensar diferente". Visou-se então, a reformulação na estrutura do perfil de carga a partir da necessidade de amenizar as variações de nível térmico, buscando melhor aproveitamento gasoso e elevação de produção. $O$ foco se orientou na direção de elevar a marcha periférica (figura 6) tendo como princípio a liberação controlada do fluxo gasoso, visando obter melhor rendimento de gás e menos escapes na carga térmica.

\subsection{Adequação da Qualidade Física das Matérias-Primas}

A grande oscilação nas frações granulométricas do sinter e coque foram destaques negativos no inicio das operações necessitando de adequação de qualidade para utilização nos fornos. A qualidade física que foi redesenhada de modo a possibilitar um melhor ajuste na distribuição do gás com a extinção das frações maiores que $80 \mathrm{~mm}$ (Figura 7) e 120mm (Figura 8) para o sinter e coque respectivamente. E a adequação do maior que $90 \mathrm{~mm}$ no coque para o máximo de $10 \%$ e no sinter o maior que $50 \mathrm{~mm}$ limitado em $5 \%$. Juntamente com o controle de finos, possibilitaram melhor controle do fluxo de gás.

\footnotetext{
* Contribuição técnica ao 44온 Seminário de Redução de Minério de Ferro e Matérias-primas, 15ํ Simpósio Brasileiro de Minério de Ferro e $2^{\circ}$ Simpósio Brasileiro de Aglomeração de Minério de Ferro, 15 a 18 de setembro de 2014, Belo Horizonte, MG, Brasil.
} 


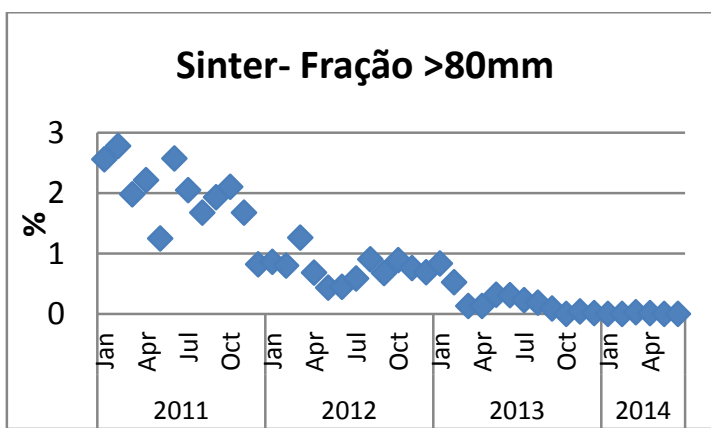

Figura 7 - Fração maior que $80 \mathrm{~mm}$ no sinter.

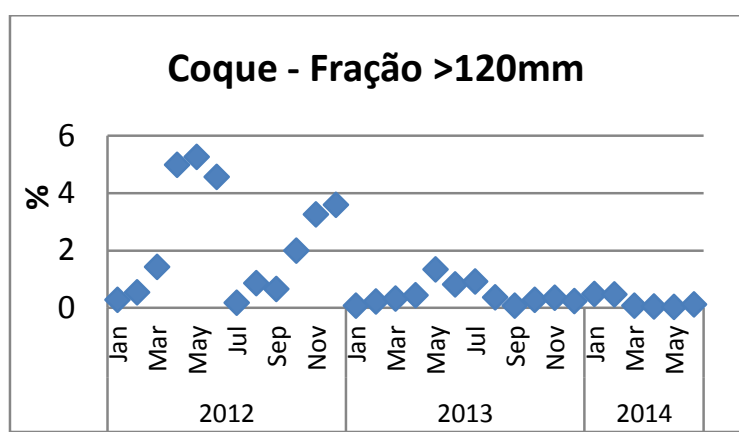

Figura 8 - Fração maior que $120 \mathrm{~mm}$ no coke.

O enquadramento da granulométrica do coque veio através da operacionalização de um sistema de britagem instalado na linha, já o sinter foi por meio da atuação no controle de processo da sinterização.

\subsection{Melhorias Operacionais na Casa de Corrida}

O layout da casa de corrida dos Altos Fornos da CSA, conforme mostrado na figura 9, são baseados em uma concepção otimizada em termos logísticos, havendo dois furos de gusa para cada forno. Dessa forma, a operação do circuito de gusa pode ser facilmente manuseada em ocasiões de necessidade na adequação da qualidade do ferro líquido. No entanto, a disposição de dois FG's no mesmo lado da área de corridas e sua inclinação reduzida, remeteu a um aprendizado operacional diante a vulnerabilidade no esgotamento/circulação de líquidos do cadinho.

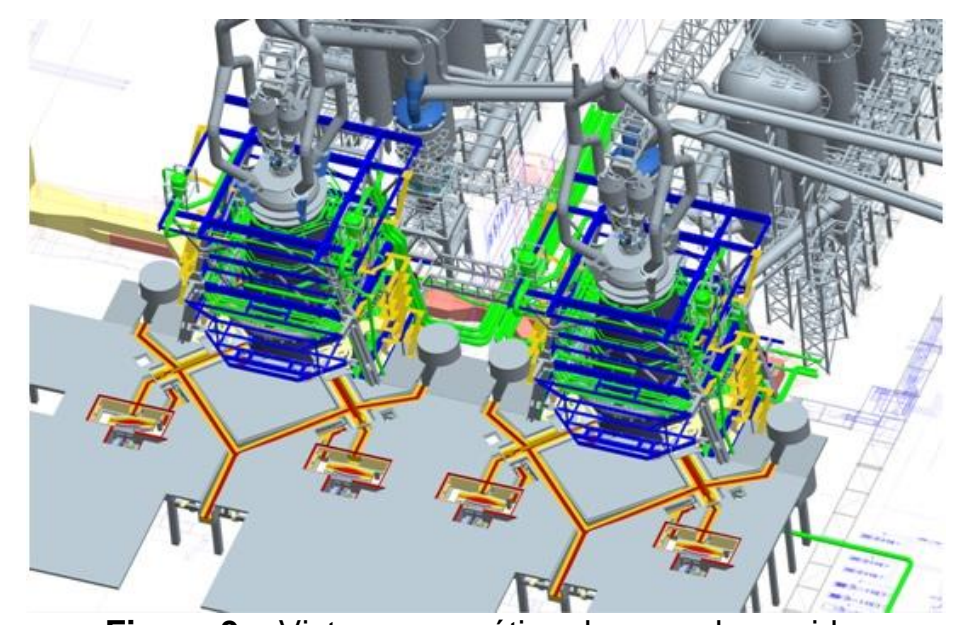

Figura 9 - Vista esquemática da casa de corrida.

A padronização das atividades no esgotamento e ajustes nos equipamentos foram essenciais para melhor desempenho do sistema.

As ações mais relevantes foram:

1. Troca do bico do canhão, facilitando a troca e flexibilizando o uso de outros modelos de bico.

2. Aumento na pressão de sopro da perfuratriz, deixando a limpeza do furo e refrigeração mais efetivas.

3. Aumento no comprimento de furo de gusa objetivado com acréscimo de $0,5 \mathrm{~m}$.

4. Aumento na disponibilidade do canal com redução de $28 \%$ no tempo de reparo.

\footnotetext{
* Contribuição técnica ao $44^{\circ}$ Seminário de Redução de Minério de Ferro e Matérias-primas, 15ํ Simpósio Brasileiro de Minério de Ferro e $2^{\circ}$ Simpósio Brasileiro de Aglomeração de Minério de Ferro, 15 a 18 de setembro de 2014, Belo Horizonte, MG, Brasil.
} 


\section{RESULTADOS E DISCUSSÃO}

A partir do desenvolvimento de controles e estreitamento dos limites de monitoramento, foi possível cercar diversos aspectos que nos levaram de forma tangível a uma redução expressiva nos consumos específicos dos combustíveis e elevação de produtividade.

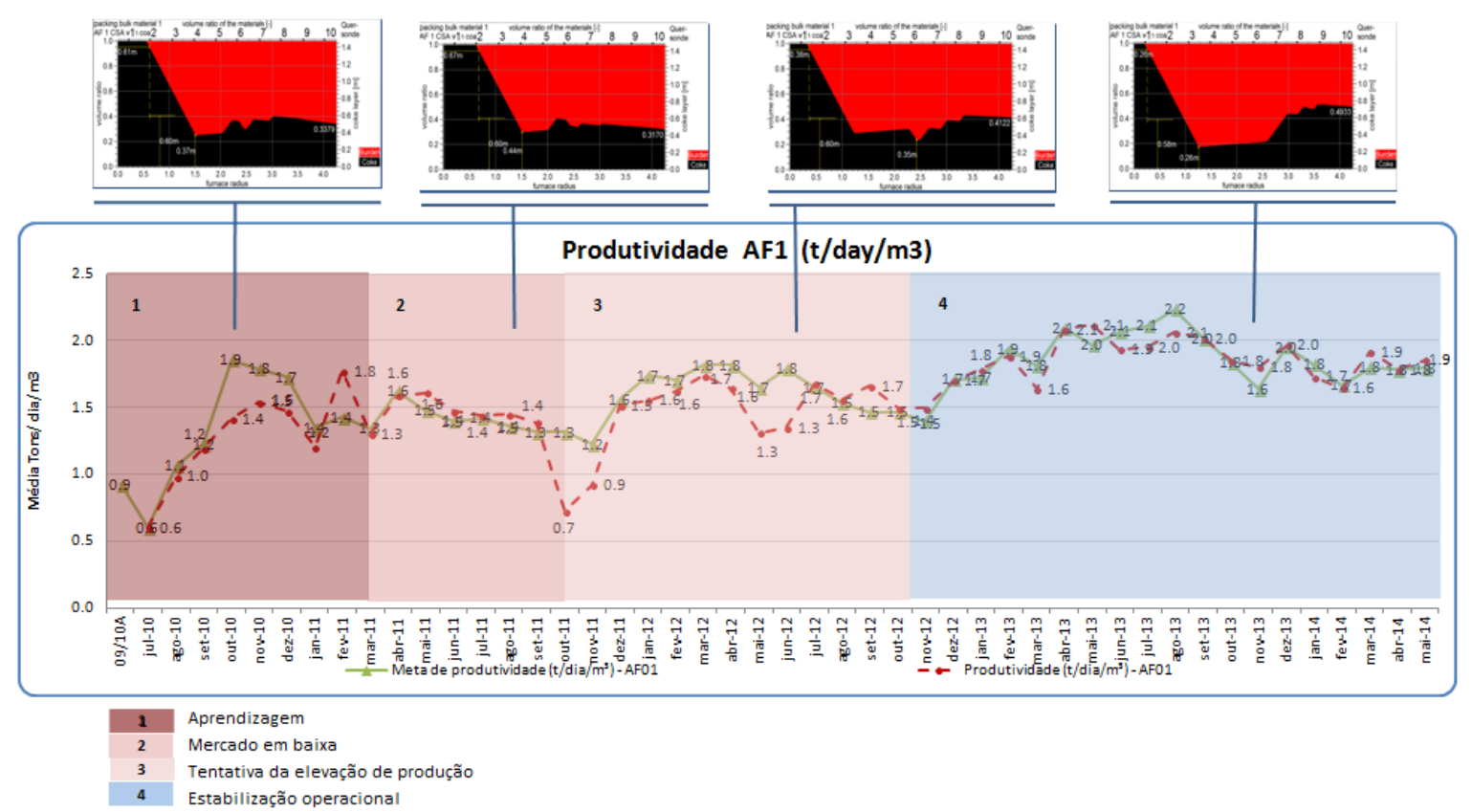

Figura 10 - Curva de elevação de produtividade desde o inicio de operação do AF01.

Inicialmente na etapa pós-blow in, a qual chamamos de fase 1 (aprendizagem) observado na Figura 10, iniciou-se uma tentativa da elevação de produtividade até o nível de $1,9 \mathrm{t} / \mathrm{d} / \mathrm{m}^{3}$. Entretanto, as inúmeras deficiências nos índices de disponibilidade e confiabilidade dos equipamentos, tornaram a tentativa mal sucedida. Assim, as equipes de produção formadas para a partida estavam expostas a grande carência de conhecimentos específicos dos sistemas produtivos.

Ao entrar na fase 2, onde temos uma etapa de redução na demanda do mercado com o start up do AF02, os níveis de produção de gusa entraram em declínio juntamente com importantes interferências. O AF01 experimentou momentos de intensas instabilidades de processo. Sendo estas, ocasionadas em parte por estar reduzido, pelas fortes oscilações na qualidade física da matéria-prima e impactos gerados por paradas emergenciais em equipamentos ou plantas da linha de produção.

Ainda na fase 3 (elevação de produção), vale observar que a distribuição de carga até meados de 2012, entraria numa zona de transição. O perfil gerado com o modelo Thybas, em destaque na Figura 10 fase 3, demonstra o principio das tentativas de migração para uma distribuição com menor camada de minério próximo a parede do forno. Em conjunto com os esforços para enquadrar as frações granulométricas do sinter e coque na fase 4 (estabilização operacional) contribuíram para os resultados favoráveis na curva de ascensão de produção e redução de combustível.

* Contribuição técnica ao $44^{\circ}$ Seminário de Redução de Minério de Ferro e Matérias-primas, 15은 Simpósio Brasileiro de Minério de Ferro e $2^{\circ}$ Simpósio Brasileiro de Aglomeração de Minério de Ferro, 15 a 18 de setembro de 2014, Belo Horizonte, MG, Brasil. 

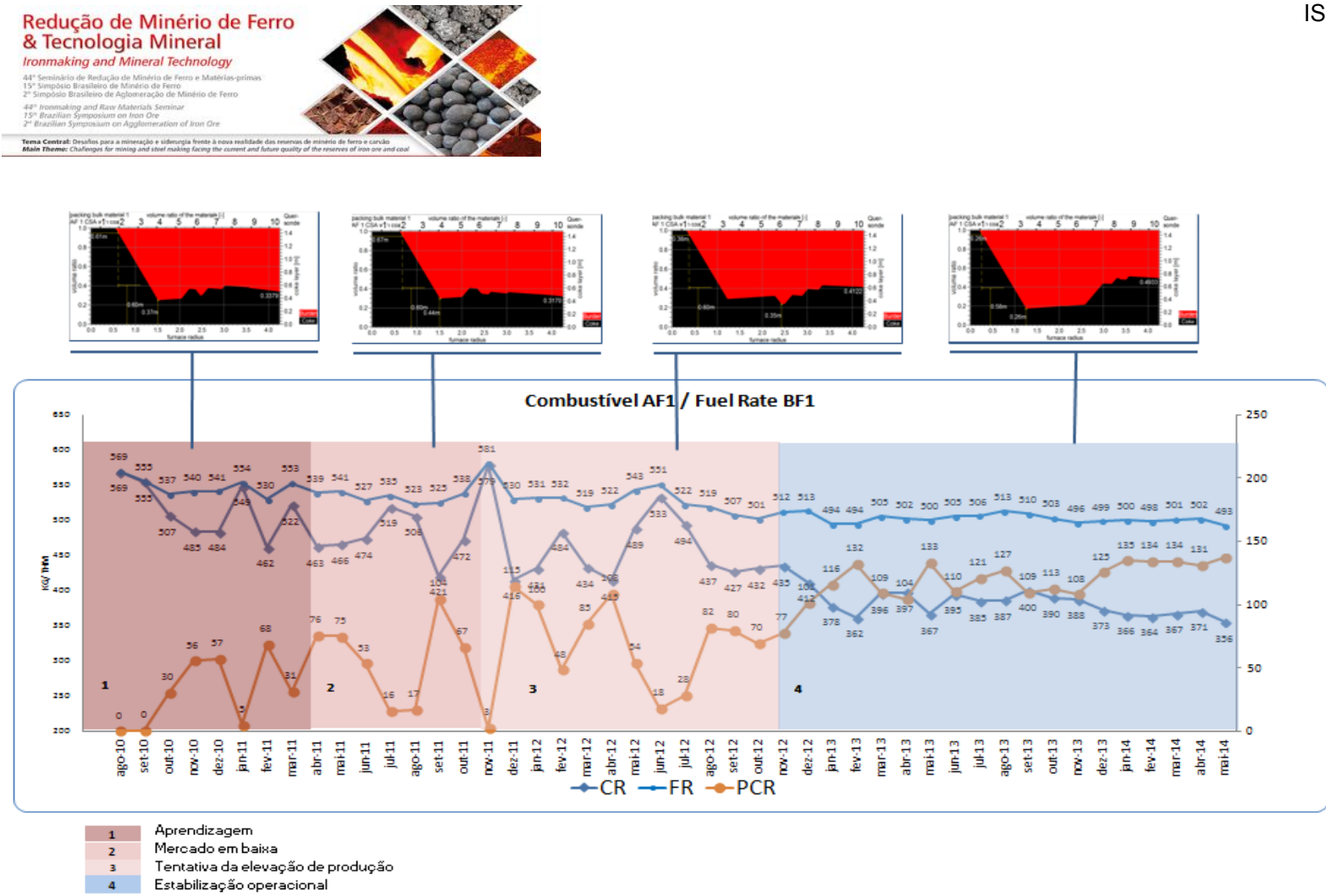

Figura 11 - Curva de redução de combustíveis. CR (Coke Rate), PCR (Pulverized Coal Rate) e FR (Fuel Rate).

A recente elevação de demanda de produção foi ponto chave para testar os limites de cada resultado atingido pelo AF01 (Figura 11). O inicio da consolidação e estabilização do processo permitiu otimizar o custo da carga metálica por meio de sucessivos incrementos no percentual de minério granulado, tendo sua limitação pela própria disponibilidade no fornecimento.

De acordo com a tabela 2, podemos encontrar um comparativo de redução de CR e FR entre os resultados médios com base em 2011. Dessa forma, através de todas as medidas adotadas visando a melhor relação entre produtividade $\mathrm{x}$ qualidade $\mathrm{x}$ custo, o AF01 da TKCSA atinge um status de boa competitividade no mercado.

Tabela 2 - Comparativo de redução de FR (Fuel Rate) e CR (Coke Rate) em referência ao ano de 2011.

\begin{tabular}{|r|c|c|r|c|c|c|}
\cline { 2 - 7 } \multicolumn{1}{c|}{} & \multicolumn{2}{c|}{ Redução de FR (Referência 2011) } & \multicolumn{3}{c|}{ Redução de CR (Referência 2011) } \\
\cline { 2 - 7 } \multicolumn{1}{c|}{} & FR & Redução & Redução & CR & Redução & Redução \\
\hline Ano & Kg/tHM & Kg/tHM & $\%$ & Kg/tHM & Kg/tHM & $\%$ \\
\hline 2011 & 538 & 0 & $0 \%$ & 483 & 0 & $0 \%$ \\
\hline 2012 & 522 & 16 & $3 \%$ & 450 & 33 & $7 \%$ \\
\hline 2013 & 503 & 35 & $7 \%$ & 385 & 98 & $20 \%$ \\
\hline 2014 & 499 & 39 & $7 \%$ & 365 & 119 & $25 \%$ \\
\hline
\end{tabular}

\section{CONCLUSÃO}

O conjunto de ações e melhorias realizadas produziu efeitos sinérgicos bem sucedidos para a elevação de produtividade e redução de combustíveis. Com isso, todo o levantamento dos dados e interpretação do desempenho do Alto-Forno 01 da CSA foram fundamentados nos seguintes aspectos:

1. Redução do número de paradas não programadas e maior confiabilidade de equipamentos proveu melhoras na continuidade operacional e estabilização dos processos e interfaces das plantas;

\footnotetext{
* Contribuição técnica ao 44 Seminário de Redução de Minério de Ferro e Matérias-primas, 15오 Simpósio Brasileiro de Minério de Ferro e 2ํ Simpósio Brasileiro de Aglomeração de Minério de Ferro, 15 a 18 de setembro de 2014, Belo Horizonte, MG, Brasil.
} 
2. O aprimoramento e desenvolvimento do sistema nível 2 foi de fundamental importância para a avaliação e controle de processo. Assim, foi possível reduzir o tempo de resposta para as atuações aos desvios operacionais;

3. A adequação dos limites de qualidade das matérias-primas contribuiu para a otimização no custo da carga metálica e redução de combustíveis;

4. Treinamento e organização da rotina operacional viabilizou uniformidade nos resultados entre equipes de turno garantindo menor vulnerabilidade a falhas operacionais;

5. Mudança na filosofia de controle térmico buscando sustentação em indicadores de processo;

6. Reformulação na estrutura da distribuição de carga baseada no controle de marcha periférica. A elevação na raiz da zona de coesão e redução do empilhamento de minério próximo a parede do AF permitiu maior domínio sobre as oscilações de carga térmica nos Staves. Dessa forma, assegurou-se melhor estabilidade, aproveitamento de gás e descida de carga com menor vulnerabilidade aos desvios de operação.

\section{Agradecimentos}

Os autores gostariam de agradecer ao Eng. Fernando Kaoru Fujihara pelo apoio técnico fornecido. Além dos colegas da Unidade Técnica da TKCSA Eng. Sandro Purcino e Eng. Carlos Emílio Citteli pela participação na conquista dos resultados.

\section{BIBLIOGRAFIA}

1 Greerdes M, Toxopeus H, Vliet CV. Modern Blast Furnace Ironmaking - An Introduction. 2a Ed. 2009. Cap. 7.

2 Hirano Aw. Relatório Técnico Mensal dos Altos Fornos. TKCSA. 2013; Jan - Dez.

3 D’Alessio J. Blast Furnace Reactions.22nd Blast Furnace Ironmaking Course. McMaster University. 2012. p.26-38.

* Contribuição técnica ao $44^{\circ}$ Seminário de Redução de Minério de Ferro e Matérias-primas, $15^{\circ}$ Simpósio Brasileiro de Minério de Ferro e $2^{\circ}$ Simpósio Brasileiro de Aglomeração de Minério de Ferro, 15 a 18 de setembro de 2014, Belo Horizonte, MG, Brasil. 